\title{
ANCHORED FALLOPIAN TUBE THROUGH THE DRAIN TUBE: A RARE CASE REPORT
}

\author{
Prezma Shrestha ${ }^{1}$, Asma Kunwar², Yasoda Rijal², Susan Aryal ${ }^{2}$, Yagya Adhikari², Shiva \\ Bhattarai $^{2}$, and Suniti Rawal ${ }^{2}$ \\ ${ }^{1}$ Tribhuvan University Teaching Hospital \\ ${ }^{2}$ Tribhuvan University Institute of Medicine
}

August 20, 2021

\begin{abstract}
Stuck drain tube is a rare postoperative complication. We present a case of 27 years female who underwent right salpingectomy with abdominal drain on left side. Postoperatively drain couldn't be removed and diagnosis of stuck drain was made. Laparotomy revealed Fallopian tube entering through both eyes of the drain tube.
\end{abstract}

\section{Introduction}

Closed suction drains are extensively used in most surgical procedure to drain serosanguineous fluid from abdominal cavity. Ruptured ectopic pregnancy is one of the common gynecological conditions where abdominal drain is used after surgical procedure. Most surgical drains are removed without any difficulties. Retained intraperitoneal drain in the immediate postoperative period is rare condition. ${ }^{1},{ }^{2}$ We present a peculiar case of stuck left intraperitoneal drain in which fallopian tube entered through one eye and escaped through adjacent eye of the drain tube. Drain was kept on left side after laparotomy done for right ruptured ectopic pregnancy.

\section{Case Description}

27 years, G3P1A1 was diagnosed as ruptured ectopic pregnancy in emergency department. She underwent emergency laparotomy with right salpingectomy and abdominal drain was kept on left side through separate incision.

On her fifth postoperative day, despite multiple attempts the drain couldn't be removed. Ultrasound revealed drain tube in the peritoneal cavity with the minimal interloop ascites. In view of stuck drain, surgery was planned to release the stuck drain tube. After skin incision of about $5 \mathrm{~cm}$, peritoneum was opened and, the drain tube was exposed. The left fallopian tube was found to be anchored inside the drain tube with the fallopian tube entering from one eye and exiting through adjacent eye. The drain was cut longitudinally from one eye to another and the stuck left fallopian tube was carefully removed. The fallopian tube was pink and healthy. The drain was removed and abdomen was closed. Patient was stable postoperatively. 


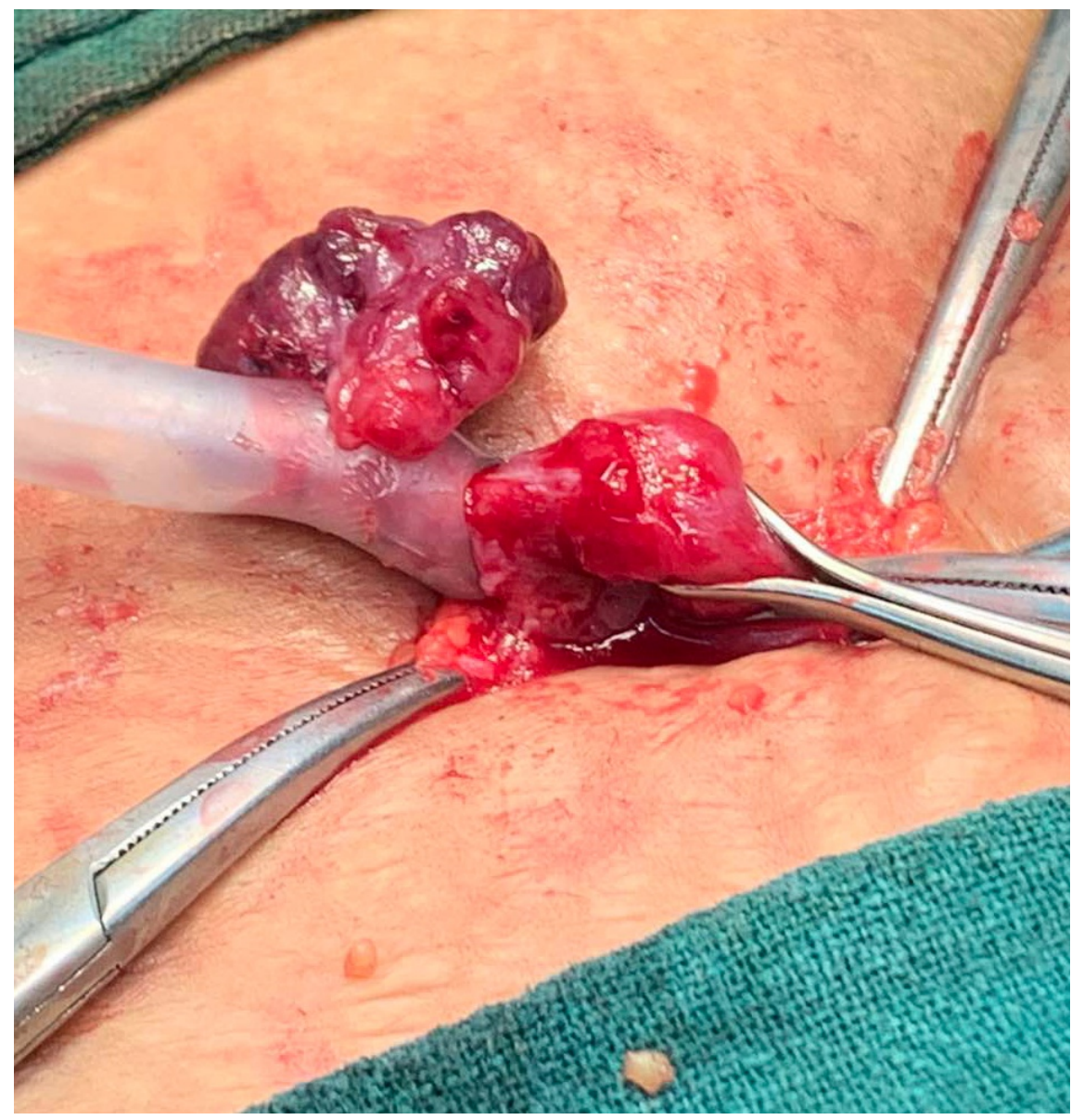

\section{Discussion}

Such anchored tube through the drain is a rare condition. To our knowledge this is the first case reported in the history. Though, other complications of drain getting entangled with intra abdominal structures, bleeding, intestinal loop strangulation or site evisceration have been reported. ${ }^{3}{ }^{4}$ Some cases may have been under-reported for the fear of medico-legal complaints. ${ }^{5},{ }^{6}$

In previous reported cases ,bowel loop and omentum were stuck in the drain tube. ${ }^{3},{ }^{5}$ Also, Richter-type hernia was formed after the loop of bowel was caught in knotted drain tube. ${ }^{7}$ In this case, fallopian tube got stuck. Salpingectomy was done in right side but drain was kept in left side. It might not have been stuck if the drain was kept on same side of salpingectomy. Delayed intervention might have lead to trauma or necrosis of the fallopian tube. Furthermore the drain must not be pulled vigorously to avoid the trauma. Drain should only be kept when absolutely indicated. Otherwise, it's wise to avoid drain placement to avoid such complication.

\section{Conclusion}

By reporting this case, we aim to highlight the possibility of entry of abdominal contents through the eye of drain tube as the potential cause of stuck drain during any kind of surgical procedures. High index of suspicion is required if the drain couldn't be removed easily. Drain, when absolutely indicated, is suggested to be kept on same side of salpingectomy.

Ethics approval and consent to participate: Not required 
Consent for publication : Written informed consent was obtained from the patient and her husband for publication of this case report and accompanying images. A copy of the written consent is available for review by the Editor-in-Chief of this journal on request.

Availability of data and materials : All the necessary data and materials are within the manuscript.

Competing interests : None to declare.

Funding : Not available.

Authors' contributions : Suniti Rawal(SR), Prezma Shrestha(PS) = Study concept, Data collection, and surgical therapy for the patient

Prezma Shrestha(PS), Asma Kunwar (AK),Yasoda Rijal (YR) = Writing- original draft preparation

Susan Aryal(SA),Yagya Raj Adhikari(YRA),Shiva Lal Bhattarai (SLB)= Editing and writing

$\mathrm{SR}$ and PS = senior author and manuscript reviewer

All the authors read and approved the manuscript.

Acknowledgments : None

\section{Authors' information (optional)}

1. Prezma Shrestha,Department of Obstetrics and Gynecology, Tribhuvan University Teaching Hospital, Kathmandu,Nepal.Email:shresthaprezma@gmail.com

2. Asma Kunwar, Department of Obstetrics and Gynecology, Tribhuvan University Teaching Hospital, Kathmandu,Nepal.Email: asmakunwar.np@gmail.com

3. Yasoda Rijal, Maharajgunj Medical Campus, Institute of Medicine, Kathmandu, Nepal. Email:rijalyasoda1221@gmail.com

4. Susan Aryal, Maharajgunj Medical Campus, Institute of Medicine, Kathmandu, Nepal. Email: susanaryal78@gmail.com

5. Yagya Raj Adhikari, Maharajgunj Medical Campus, Institute of Medicine, Kathmandu, Nepal. Email:yagyaraj834@gmail.com

6. Shiva Lal Bhattarai, Maharajgunj Medical Campus, Institute of Medicine, Kathmandu, Nepal. Email:doccvabhattarai@gmail.com

7. Suniti Rawal, Department of Obstetrics and Gynecology Tribhuvan University Teaching Hospital, Kathmandu, Nepal. Email:sanudinurawal@yahoo.com

Closed suction drains are

usually inserted via a separate stab wound at a site

remote from the original incision. The drains are

usually removed on the ward after $24-72 \mathrm{~h}$

\section{REFERENCES}

1. Hills AJ, Armstrong D, Bisase B, Norris P. Fragments of drains retained during operations on the temporomandibular joint. Br J Oral Maxillofac Surg . 2019;57(3). doi:10.1016/j.bjoms.2018.12.015

2. Koaban S, Alatassi R, Alogayyel N. A forgotten retained drain inside a knee for 10 years: A case report. Int J Surg Case Rep . 2018;48. doi:10.1016/j.ijscr.2018.05.014

3. Pagoti R, Arshad I, Schneider C. Stuck redivac drain: To open or not to open? A case report. Aust New Zeal J Obstet Gynaecol . 2008;48(2). doi:10.1111/j.1479-828X.2008.00849.x

4. Yska M, van Migem P. [A man stuck to a drain]. Ned Tijdschr Geneeskd . 2012;156(5). 
5. Liao CS, Shieh Min-Chieh MC. Laparoscopic retrieval of retained intraperitoneal drains in the immediate postoperative period. J Chinese Med Assoc . 2011;74(3). doi:10.1016/j.jcma.2011.01.030

6. Downing R, Wilkinson A, Alexander-Williams J. Knotted drainage tube: An unusual postoperative complication. Br J Surg . 1977;64(9). doi:10.1002/bjs.1800640913

7. Ross AP. Knotted drainage tube: practical points in its prevention. Ann R Coll Surg Engl . 1984;66(5).

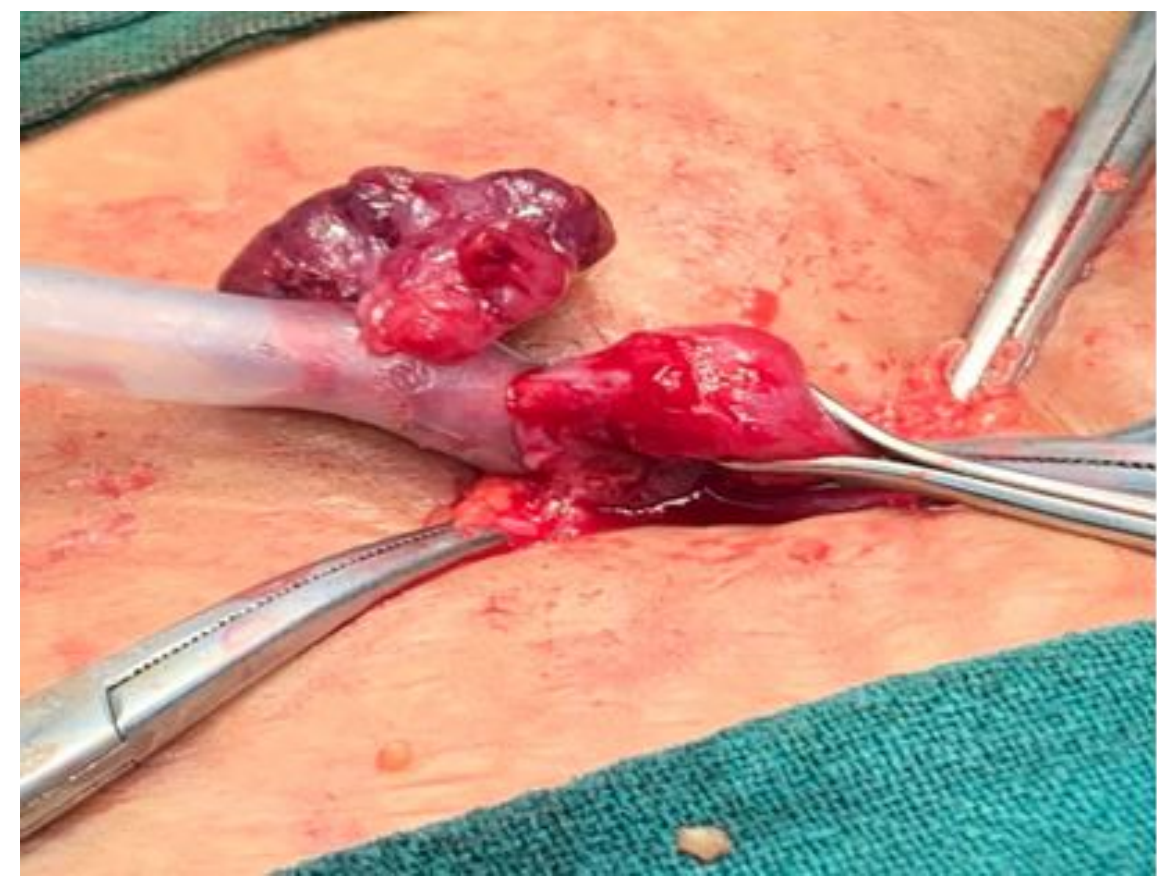

